\title{
On the ground motion around epicentral area of earthquakes having magnitude 6 class
}

\author{
By Choshiro TAmura*) and Shunzo OKamoto, M. J.A.
}

(Communicated Jan. 12, 1998)

\begin{abstract}
In response to lessons learned from the damage to structures in the epicentral area of the Hyogo-ken Nanbu Earthquake of 1995, the high-density installation of seismometers has been carried out in Japan. These seismometers have provided the intensities of many subsequent earthquakes. This paper presents a report on the results of the analysis of earthquake intensities observed in and around the epicentral areas of six magnitude 6 class earthquakes in the four areas.
\end{abstract}

Key words: Earthquake motion; max. acceleration; magnitude 6; distance attenuation.

Introduction. Estimations of earthquake motion acting on structures are based on records of actual earthquake motion and on the analysis of such records.

In many cases, earthquake motion is estimated based on earthquake magnitudes recorded in historical documents, epicenter (or hypocenter) distance, and the mechanical properties of the ground under consideration. Particularly close attention must be paid to the strength of the earthquake motion in and around the epicentral area and the characteristics of its damping over distance. Even earthquakes with a magnitude of 6 occasionally cause severe disasters in their epicentral areas. The earthquake motion in this range is determined by the hypocenter mechanism, extent of the fault, the geological structure, state of the surface ground, etc., and is, therefore, an extremely complex phenomenon. The authors, who have been interested in this problem for a long time, have continued to study it and proposed a number of formulae. ${ }^{1)}$

But it rarely happens that the earthquake records of big earthquakes can be obtained in its epicentral area before seismometers have been densely distributed in the country.

The Hyogo-ken Nanbu Earthquake of 1995 caused extensive damage in parts of its epicentral area in the middle of the City of Kobe. In response, the Government of Japan decided to create a dense earthquake observation network throughout Japan. Seismographs installed throughout Japan at more than 900 locations between 20 and 25 kilometers apart provide strong motion records

*) Department of Civil Engineering, College of Industrial Technology, Nihon University, Narashino 275-8575, Japan. (acceleration). This system started operating in June 1996 and has already recorded a number of magnitude 6 earthquakes occurring inland.

This paper describes the results of analyses based on K-net data concerning magnitude 6 earthquake motion, primarily the damping over distance of the maximum acceleration in and around epicentral areas.

Outline of the earthquakes analyzed. The epicenters of the earthquakes analyzed as part of this study are distributed throughout Japan except in Hokkaido. Specifically, they are located at four locations: one each in north-eastern Honshu, central Honshu, western Honshu, and southern Kyushu. One $\sim$ three magnitude 6 earthquakes have occurred at each point. Characteristics of the observed earthquake are shown in Table I.

Outlines of each follow.

Location A. Close to the border betweeen Miyagi Prefecture and Akita Prefecture in northeastern Honshu, three earthquakes $\left(A_{1}\right.$ to $\left.A_{3}\right)$ occurred in succession on August 11, 1996.

The locations of the epicenters of $A_{1}$ and $A_{2}$ are 2.5 $\mathrm{km}$ apart in the east to south east direction and the locations of the epicenters of $A_{2}$ and $A_{3}$ are $5 \mathrm{~km}$ apart to the south.

Most of the damage to structures occurred within a range of approximately $8 \mathrm{~km}$ from earthquake $A_{3}$. The major damage included damage to bridges and houses. Earthquake motion generated by earthquakes $A_{1}$ and $A_{3}$ at this location were studied. A typical wave form is the Naruko location acceleration wave form shown in Fig. 1 (epicentral distance of $13 \mathrm{~km}$ from the $\mathrm{A}_{1}$ earthquake).

Location $B$. An earthquake with its epicenter in the 
Table I

\begin{tabular}{|c|c|c|c|c|c|c|}
\hline No. & & Date/Time & Epicenter Location & Depth & Magnitude & Maximum acceleration \\
\hline $\mathrm{A} 1$ & Aug. & 11, 1996 & $38^{\circ} 55^{\prime} \mathrm{N}, 140^{\circ} 38^{\prime} \mathrm{E}$ & $7 \mathrm{~km}$ & 5.9 & $464 \mathrm{gal}(\Delta=13 \mathrm{~km})$ \\
\hline $\mathrm{A} 2$ & Aug. & $11,1996 \quad 3: 54$ & $38^{\circ} 54^{\prime} \mathrm{N}, 140^{\circ} 40^{\prime} \mathrm{E}$ & $10 \mathrm{~km}$ & 5.4 & $305 \mathrm{gal}(\Delta=13 \mathrm{~km})$ \\
\hline A3 & Aug. & $11,1996 \quad 8: 10$ & $38^{\circ} 52^{\prime} \mathrm{N}, 140^{\circ} 41^{\prime} \mathrm{E}$ & $10 \mathrm{~km}$ & 5.7 & 319 gal $(\Delta=14 \mathrm{~km})$ \\
\hline B & March & $16,199714: 51$ & $34.9^{\circ} \mathrm{N}, 137.5^{\circ} \mathrm{E}$ & $39 \mathrm{~km}$ & 5.8 & $525 \mathrm{gal}(\Delta=10 \mathrm{~km})$ \\
\hline $\mathrm{C}$ & June & $25,199718: 50$ & $34.4^{\circ} \mathrm{N}, 131.7^{\circ} \mathrm{E}$ & $20 \mathrm{~km}$ & 5.9 & $421 \mathrm{gal}(\Delta=10 \mathrm{~km})$ \\
\hline D1 & March & $26,1997 \quad 17: 31$ & $31^{\circ} 59^{\prime} \mathrm{N}, 130^{\circ} 22^{\prime} \mathrm{E}$ & $8 \mathrm{~km}$ & 6.3 & $727 \mathrm{gal}(\Delta=11 \mathrm{~km})$ \\
\hline D2 & April & $3,1997 \quad 4: 33$ & $31^{\circ} 59^{\prime} \mathrm{N}, 130^{\circ} 22^{\prime} \mathrm{E}$ & $10 \mathrm{~km}$ & 5.5 & $218 \mathrm{gal}(\Delta=28 \mathrm{~km})$ \\
\hline D3 & May & 13, 1997 14:38 & $31^{\circ} 54^{\prime} \mathrm{N}, 130^{\circ} 18^{\prime} \mathrm{E}$ & $10 \mathrm{~km}$ & 6.2 & $902 \mathrm{gal}(\Delta=16 \mathrm{~km})$ \\
\hline
\end{tabular}

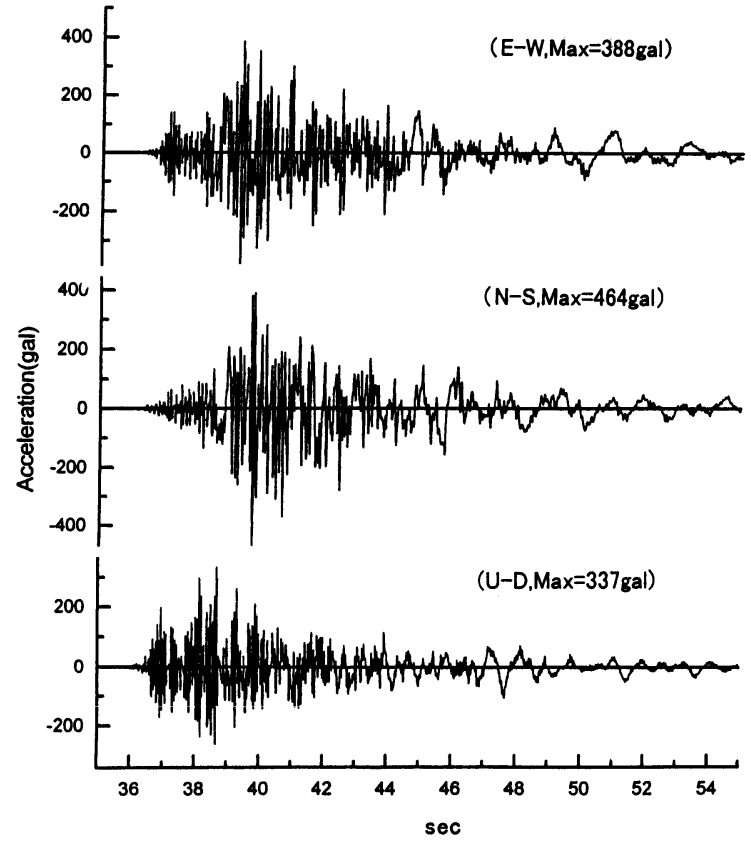

Fig. 1. Accelerograms at Naruko-cho, Miyagi-Pref., Earthquake of 3:12, August 11, 1996.

eastern part of Aichi Prefecture.

This earthquake inflicted only light damage. Fig. 2 shows the acceleration wave form at Tsukude where the maximum acceleration was recorded.

Location $C$. The epicenter of this earthquake was near the boundary of Yamguchi Prefecture and Shimane Prefecture in western Honshu. Fig. 3 shows the acceleration wave form at the Tsuwano seismograph location where the maximum acceleration was recorded.

Location $D$. A series of three magnitude 6 class earthquakes occurred in the Satsuma region of northwestern Kagoshima Prefecture in Kyushu.

$D_{2}$ is assumed to be an aftershock of $D_{1}$, but $D_{3}$ is an independent earthquake. According to information released immediately after $D_{1}$ it resulted in one serious injury, caused minor injuries to 30 people, totally
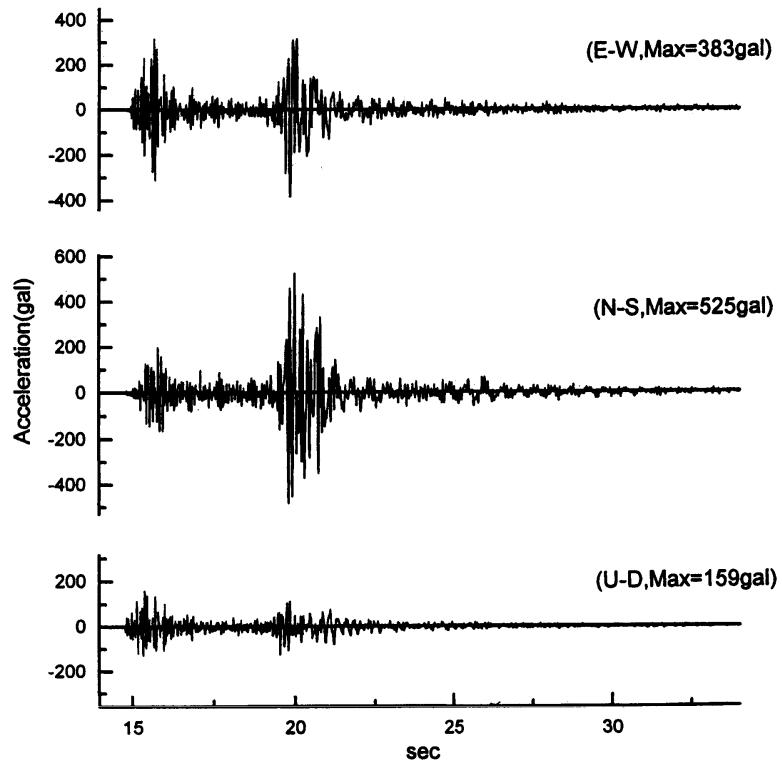

Fig. 2. Accelerograms at Tsukude-cho, Aichi-Pref., Earthquake of 14:51, March 16, 1996.

destroyed two homes, partly destroyed 4 more, caused partial damage to approximately 1,720 homes, cracked columns in some reinforced concerete school buildings, and caused quay walls in ports and fishing harbors to lean or subside. It also collapsed road slopes. The range of most of this damage appears to be within about 20 kilometers from the epicenter.

This report describes studies of $D_{1}$ and $D_{3}$. Fig. 4, which shows the acceleration wave form for $D_{1}$ at Izumi city $(\Delta=13 \mathrm{~km})$, indicates the maximum acceleration.

Distance attenuation of the maximum acceleration. This chapter describes the characteristics of the damping of the maximum acceleration over distance at each location.

Location A. On Fig. 5, which presents the observation points in and near the epicentral area, the epicenter is indicated by an $\mathrm{X}$. The straight line joining the observation points was drawn to represent the almost radial transmis- 


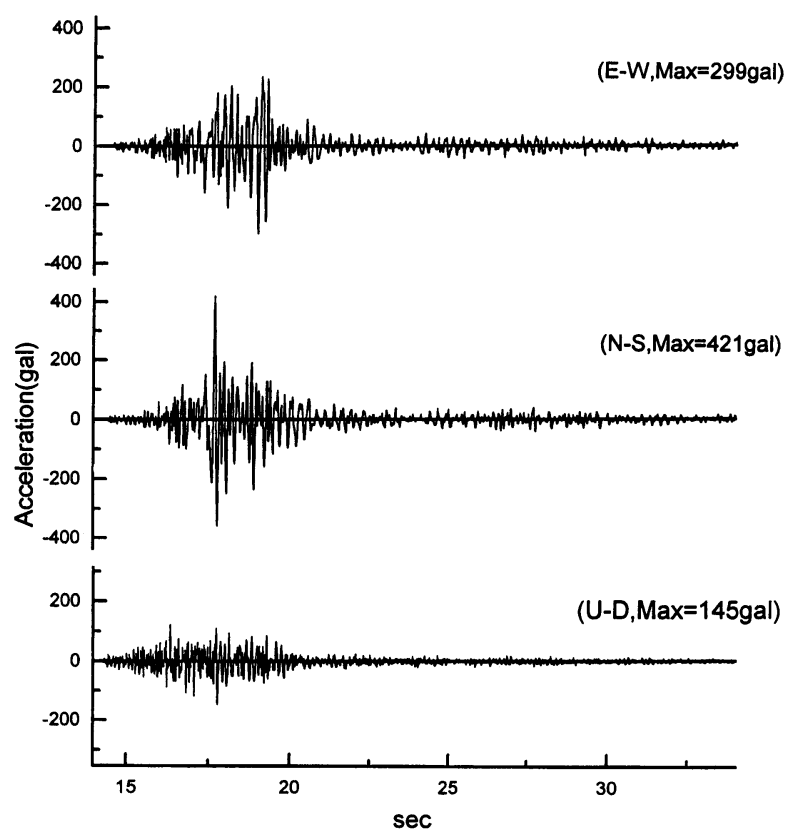

Fig. 3. Accelerograms at Tsuwano-cho, Shimane-Pref., Earthquake of 18:50, June 25, 1997.
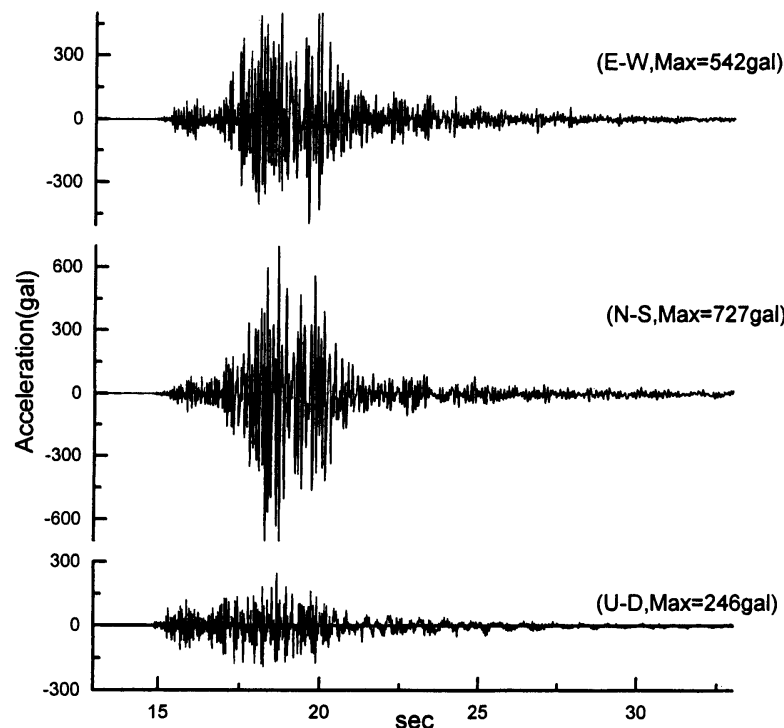

Fig. 4. Accelerograms at Izumi-city, Kagoshima-Pref., Earthquake of 17:31, March 26, 1997.

sion of the earthquake motion from the epicenter.

Fig. 6 represents the maximum accelerations for the horizontal direction of earthquake $A_{1}$ and shows its correspondence with epicentral distance. The broken line joining the maximum values corresponds to the broken line in Fig. 5.

If the epicentral distance (hereafter represented by the symbol $\Delta$ ) in Fig. 6 is limited to a range of $70 \sim 80 \mathrm{~km}$,

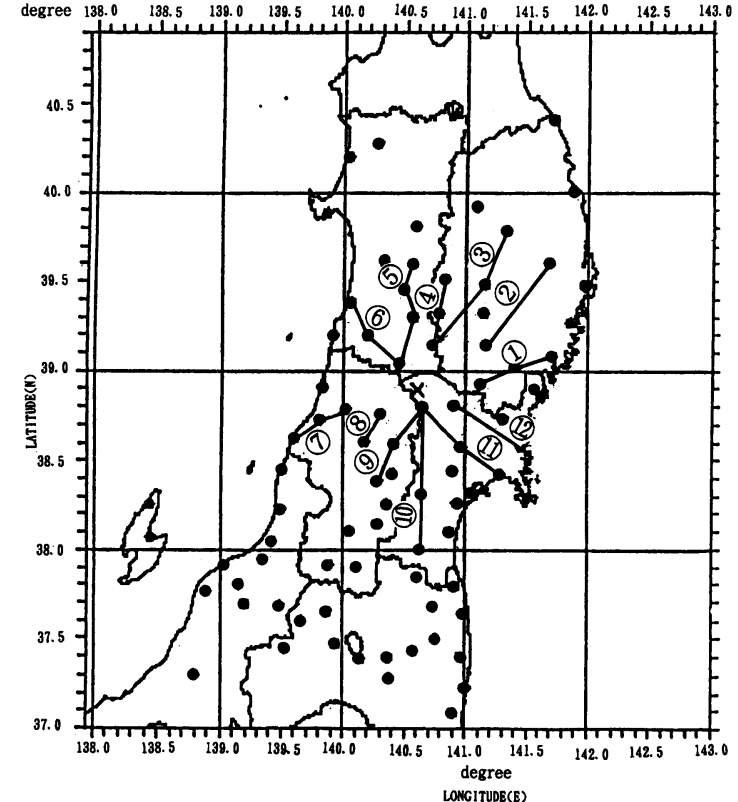

Fig. 5. Epicenter, observation points and broken lines linking the points on the radial direction from the epicenter.

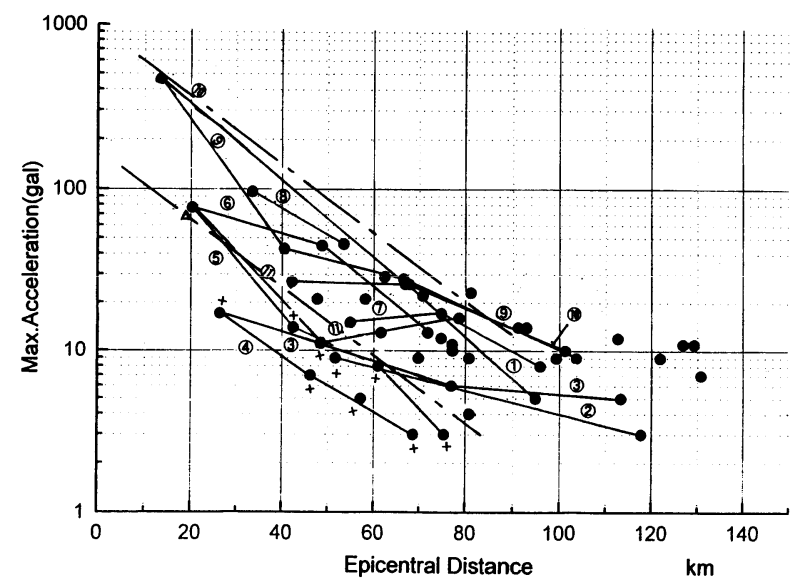

Fig. 6. Max. accelerations and epicentral distance of earthquake, 3:12, August 11, 1996.

the following facts are known.

1) In the group of maximum accelerations distributed in a belt enclosed by almost straight lines falling to the right, among the 9 points on the bottom edge of the group between $\Delta=30 \mathrm{~km}$ to $90 \mathrm{~km}, 7$ points (marked by + in the Figures) are concentrated in a single area on the north side of the epicenter and are the only observation points in this area. The same pattern was observed in the observations of both earthquakes $A_{1}$ and $A_{3}$, a similarity probably caused by local characteristics. Aside from these 7 points, the width of the belt is extremely contracted.

2) The gradient of the broken line connecting the 


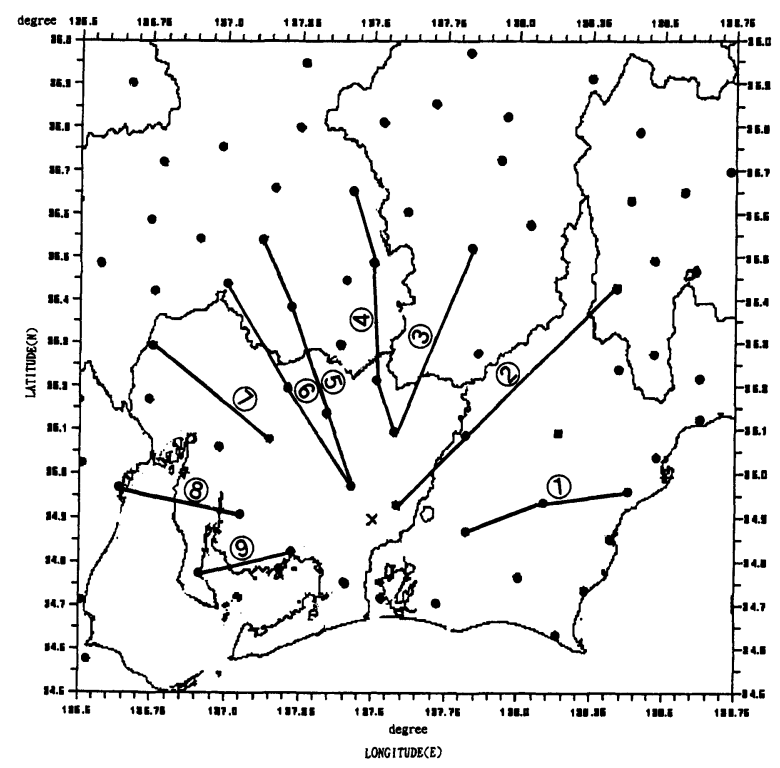

Fig. 7. Epicenter, observation points and broken lines linking the points on the radial direction from the epicenter.

observed values, almost a constant gradient aside from a few exceptional cases, resembles the gradient of the straight lines enclosing the belt-shaped zone.

3) The $\Delta$ symbol is the maximum acceleration of the bed rock (within a tunnel) at a dam (arch type) site. A comparison of the maximum acceleration in solid rock with that in other kinds of ground reveals that in many cases, it is the smallest value if exceptions are presumed to be the result of liquefaction etc. This is believed to be a result of the dynamic characteristics of the surface ground.

4) The maximum acceleration in the belt-shaped zone can be represented by the following formula based on the above conclusions.

$$
\log _{10} \alpha_{\max }=\log _{10} K_{1}-\frac{\Delta}{K_{2}}
$$

Where:

$$
\begin{aligned}
\alpha_{\text {max }}: \text { Maximum acceleration (gal) } \\
\Delta: \text { Epicentral distance }(\mathrm{km}) \\
\mathrm{K}_{1}, \mathrm{~K}_{2}: \text { Constants }
\end{aligned}
$$

For earthquake $A_{3}$ the similar relation to earthquake $A_{1}$ exists between $\alpha_{\mathrm{m}}$ and $\Delta$. For earthquake $\mathrm{A}_{1}, \mathrm{~K}_{1}=170 \sim$ 1000 , while for $A_{3}, K_{1}=170 \sim 1100$, with $K_{2}=48$ in both cases.

Location $B$. As in the case of 1 , the epicenter and observation points are shown in Fig. 7 while the maximum acceleration is shown in Fig. 8. The broken lines in Fig. 7 and Fig. 8 have the same significance. Figs. 7 and 8 reveal

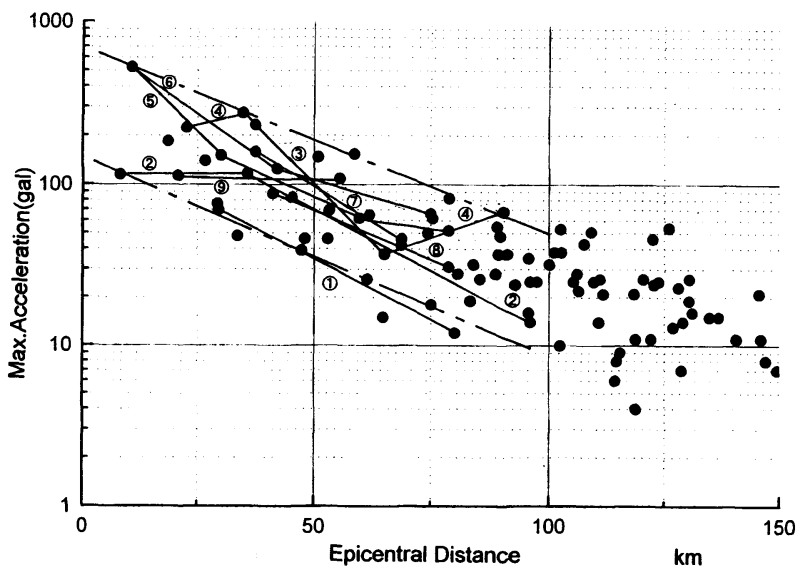

Fig. 8. Max. accelerations and epicentral distance of earthquake, 14:51, March 16, 1997.

the following facts.

1) The maximum acceleration is distributed in the belt shaped zone falling to the right. If $\Delta$ is restricted to a range of about $90 \mathrm{~km}$, it is almost enclosed by two parallel straight lines, and the ratio of the values of the bottom edge and the top edge ranges from 5 to 6 times excluding a few exceptions. But the points on the bottom edge of this belt-shaped distribution are all located in regions along the seashore. This is considered a characteristic of this region, and its ratio is reduced to between 4 and 5 times with a few exceptions.

2) The gradients of the broken lines in Fig. 8 can be viewed as almost parallel excluding a few exceptions, and if $\Delta$ is limited to within about $90 \mathrm{~km}$, it is possible to view the gradients of the two straight parallel lines as almost identical.

3) If the upper limit and lower limit of the belt-shaped zone are shown as mutually parallel straight lines (chain lines in the Figure), they are presented in the form of formula [1].

$$
\log _{10} \alpha_{m}=\log _{10}(180 \sim 800)-\frac{\Delta}{70}
$$

Location $C$. As in the case of 1 , the observation points and the epicenter are shown in Fig. 9 and the maximum acceleration in Fig. 10.

The broken line in Fig. 11 includes a part whose gradient is partially reversed. This is assumed to reflect big differences in the surface ground. Because they are overall almost identical gradients falling to the right, $\alpha_{\mathrm{m}}$ $-\Delta$ relationship is approximated by the following formula as it is in the case of formula [1] in 1 .

$$
\log _{10} \alpha_{m}=\log _{10}(100 \sim 500)-\frac{\Delta}{75}
$$




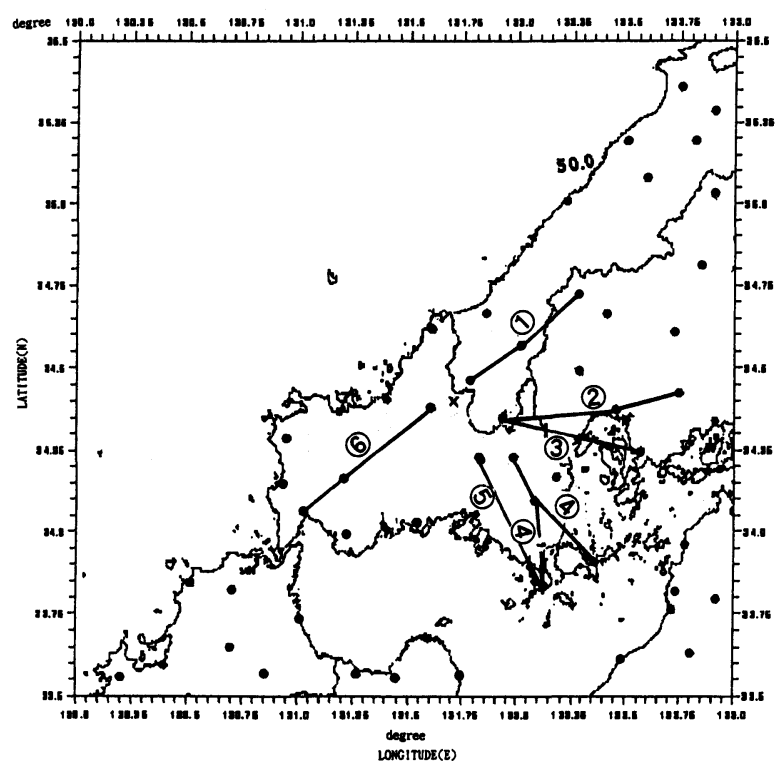

Fig. 9. Epicenter, observation points and broken lines linking the points on the direction from the epicenter.

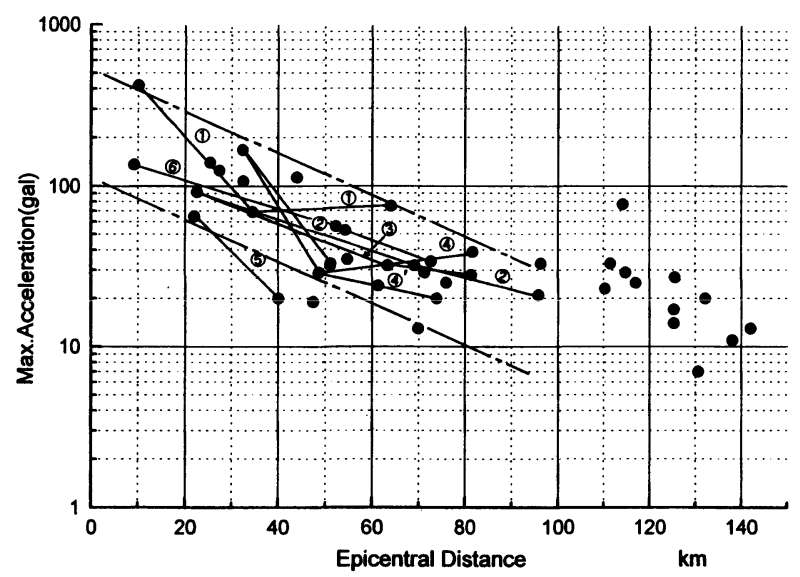

Fig. 10. Max. accelerations and epicentral distance of earthquake, 18:50, June 25, 1997.

Location $D$. Fig. 11 shows the observation points and the epicenter while Fig. 12 shows the maximum acceleration.

As explained above, if the $\Delta$ is limited to within about $90 \mathrm{~km}$, the maximum acceleration line is included between two straight lines falling to the right. But in Fig. 12 (a) and (b), the observation points for the five values (marked by + in the Figures) along the top edge between $\Delta=60 \mathrm{~km}$ to $90 \mathrm{~km}$ are in all cases along the seacoast of the Satsuma Peninsula, a result believed to be caused by the regional characteristics or the geological characteristics of this part of Kagoshima Prefecture. Excluding these five, sharply improves the harmony between the straight lines.

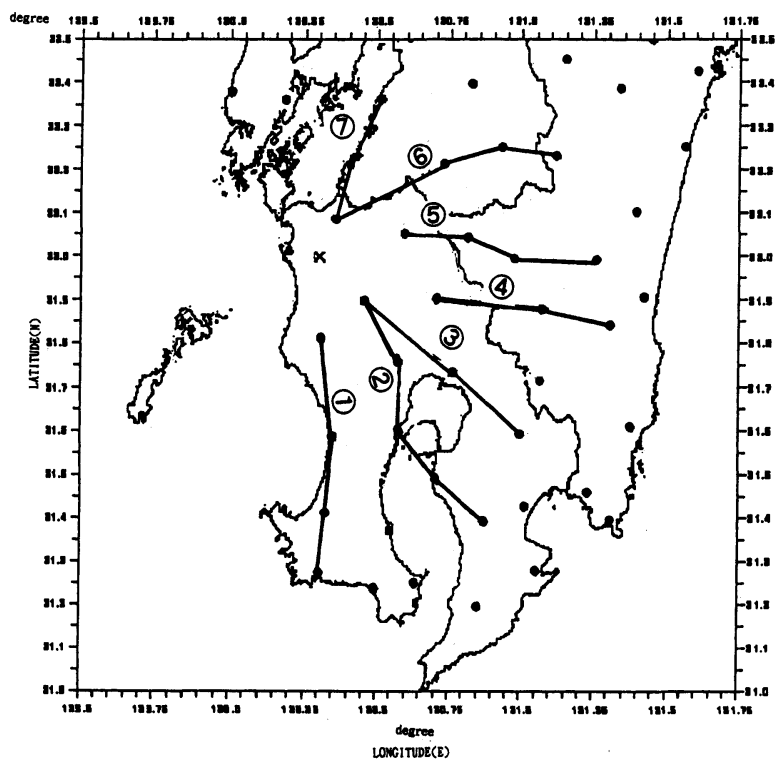

Fig. 11. Epicenter, observation points and broken lines linking the points on the radical direction from the epicenter.
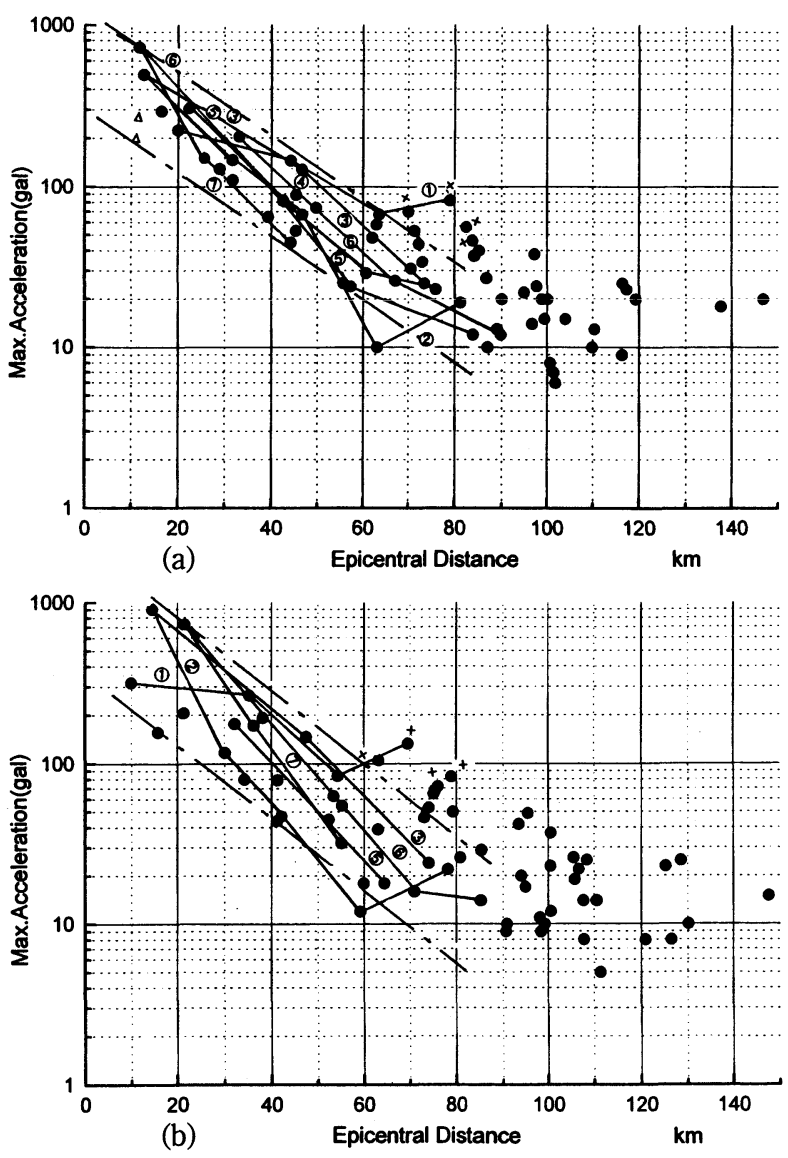

Fig. 12. (a) Max. accelerations and epicentral distance of earthquake, 17:31, March 26, 1997. (b) Max. accelerations and epicentral distance of earthquake, 14:38, May 13, 1997. 
In Fig. 12 (a), the $\Delta$ symbol is the value in the bed rock at the site of a dam, and as in the case of 1 , it is the value at the lowest point in the belt-shaped distribution.

The following formulae represent $\alpha_{\mathrm{m}}-\Delta$ relationship as in formula.

For Earthquake $\mathrm{D}_{1}$ :

$$
\log _{10} \alpha_{m}=\log _{10}(220 \sim 1100)-\frac{\Delta}{60}
$$

For Earthquake $D_{3}$ :

$$
\log _{10} \alpha_{m}=\log _{10}(220 \sim 1500)-\frac{\Delta}{55}
$$

Summarization. The following are the results of a study of the maximum acceleration-epicentral distance relationship of earthquake motion in and around the epicentral area of six recent magnitude 6 class earthquakes at four locations in Japan.

The study revealed the following information.

1) It can be concluded that within an epicentral distance range between about $80 \mathrm{~km}$ and $90 \mathrm{~km}$, the maximum acceleration is distributed between two mutually parallel straight lines. The maximum acceleration can be approximated using the following formula.

$$
\log _{10} \alpha_{\max }=\log _{10} K_{1}-\frac{\Delta}{K_{2}}
$$

Where:

$$
\begin{aligned}
\alpha_{\max } & \text { Maximum acceleration (gal) } \\
\Delta & : \text { Epicentral distance }(\mathrm{km}) \\
\mathrm{K}_{1}, \mathrm{~K}_{2} & \text { : Constants }
\end{aligned}
$$

2) The maximum acceleration rapidly declines as the epicentral distance rises. In this example, it is damped at an average rate of about $1 / 2$ every $14 \sim 17 \mathrm{~km}$. This rate contrasts sharply with the rates for earthquakes in the magnitude 7 calss and higher.

3) The maximum acceleration value varies by roughly 5 times even at the same epicentral distance. It is assumed that the ground-earthquake motion relationship has a significant influence on this, but more study of this issue is necessary.

4) There are cases where regional characteristics appear. As past research has shown, it is known that earthquake motion is not very powerful in areas extremely close to the fault. Consequently, it may be appropriate to also determine the maximum acceleration at the edge of an epicentral area. If this is contrasted with the distribution of damage described in Chapter Two, it may be possible that damage occurs at a maximum acceleration of approximately 600 gal. In either case, more study is necessary.

Acknowledgements. Finally, in addition to stating that information provided by K-net was used for this study, the authors wish to express their deep gratitude to $\mathrm{T}$. Makino and $\mathrm{H}$. Hoshi, graduate students of the College of Industrial Technology, Nihon University for assisting with the organization of this information.

\section{Reference}

1) Okamoto, S. (1984) Introduction to Earthquake Engineering, University of Tokyo Press. 